\title{
THE ACCURACY OF THE NAVIGATIONAL ACCELEROMETER WITH A NONLINEAR METROLOGICAL MODEL IN OPERATING CONDITIONS
}

\author{
Mycola Chernyak, Vadym Kolesnyk \\ Institute of Aerospace Technologies, National Technical University of Ukraine \\ "Igor Sikorsky Kyiv Polytechnic Institute", Peremogy av., 37, build. 28, Kyiv, Ukraine \\ chernyak_dk@ukr.net•ORCID: 0000-0002-3615-8745 \\ k.vadim888@gmail.com • ORCID: 0000-0002-3209-5513
}

\begin{abstract}
A mathematical model of the error of the navigational accelerometer caused by the nonlinearity of its metrological model, taking into account the influence of vibration, was developed. The method of experimental estimation of the vibration error based on the developed model was proposed. The main idea of the method is to evaluate parameters of the developed model during static tests in the terrestrial gravitational field and to calculate error according to the specific vibration characteristics - the amplitude in the case of harmonic vibration profile or the frequency band and the power spectral density in the case of random vibration. The effectiveness of the proposed method has been tested using three types of navigation accelerometers in comparison with the results of classical dynamic testing in various vibration conditions (harmonic, white noise, etc.).
\end{abstract}

Keywords: navigational accelerometer, vibration error, metrological model, conversion function, identification of coefficients, static test.

\section{INTRODUCTION}

The basis of any inertial navigation system or airborne orientation system is navigation accelerometers, which give of information about the linear acceleration of an object. Ideally, the output signal of the accelerometer should be proportional to the projection of the apparent acceleration on its sensitivity axis. However, in operating conditions, it contains errors caused by both environmental factors (temperature, magnetic fields, etc.) and nonlinearity of the metrological model. Also, during onboard flying, there are always vibrations of a different character, from the harmonic oscillation of the aircraft center of mass to the random faltering of aircraft structural elements with a wide frequency range. The constant component of the vibration acceleration detected on the nonlinearities of the accelerometer's metrological model, which cause additional vibration error (VE) appearance [1].

Unfortunately, there are currently no standardized methods for monitoring and evaluating. Often, the developers do not aim to find any functional relationship and present the result of calculations in the form of the law of distribution of the magnitude of the VE to evaluate the information capacity of the accelerometer on this probable characteristic [2]. 
Compensation of vibration error obtained by introducing detection value which depends only on the square of the vibration magnitude [3]. This simplification explained by the fact that the vibration test in the frequency passband effects incredible difficulties caused by a large number of vibration parameters which values vary greatly.

\section{PROBLEM STATEMENT}

The purpose of this paper is to develop a method of determining the value vibrational error navigational accelerometer caused by nonlinearity its metrological model, which allows you to identify this error in its static tests like and are mandatory for each accelerometer produced.

\section{RESULTS}

\section{The error model of the navigational accelerometer with nonlinear metrological model}

The mathematical model of vibration error is based on the IEEE Std. 1293-1998 [4] metrological model of the output signal of the navigational accelerometer

$U(\vec{a})=K_{1}\left\{\begin{array}{l}k_{0}+\left(1+\frac{k_{1}^{\prime}}{2} \operatorname{sign} a_{\mathrm{IA}}\right) \cdot a_{\mathrm{IA}}+\sum_{n \geq 2} k n a_{\mathrm{IA}}^{n}+\delta_{\mathrm{OA}} a_{\mathrm{PA}}+ \\ +\delta_{\mathrm{PA}} a_{\mathrm{OA}}+k_{\mathrm{IP}} a_{\mathrm{IA}} a_{\mathrm{PA}}+k_{\mathrm{IO}} a_{\mathrm{IA}} a_{\mathrm{OA}}+k_{\mathrm{PO}} a_{\mathrm{PA}} a_{\mathrm{OA}}+\varepsilon\end{array}\right\},[$ out $]$

where: $K_{1}$, [out/g] is the coefficient of sensitivity (CS); $k_{0}$, [g] - zero offset; $k_{1}^{\prime}$, [1] - sensitivity asymmetry; $\delta_{\mathrm{OA}}, \delta_{\mathrm{PA}}$, $[\mathrm{rad}]$ - angles of non-orthogonality of the OA and PA axes with the IA axis (Fig. 1); $k_{n}(n \geq 2),\left[1 / g^{n}\right]-$ nonlinearity coefficients; $k_{\mathrm{IP}}, k_{\mathrm{IO}}, k_{\mathrm{PO}},[1 / g]-$ cross-sensitivity coefficients; $\varepsilon,[g]-$ measurement and non-simulated errors.

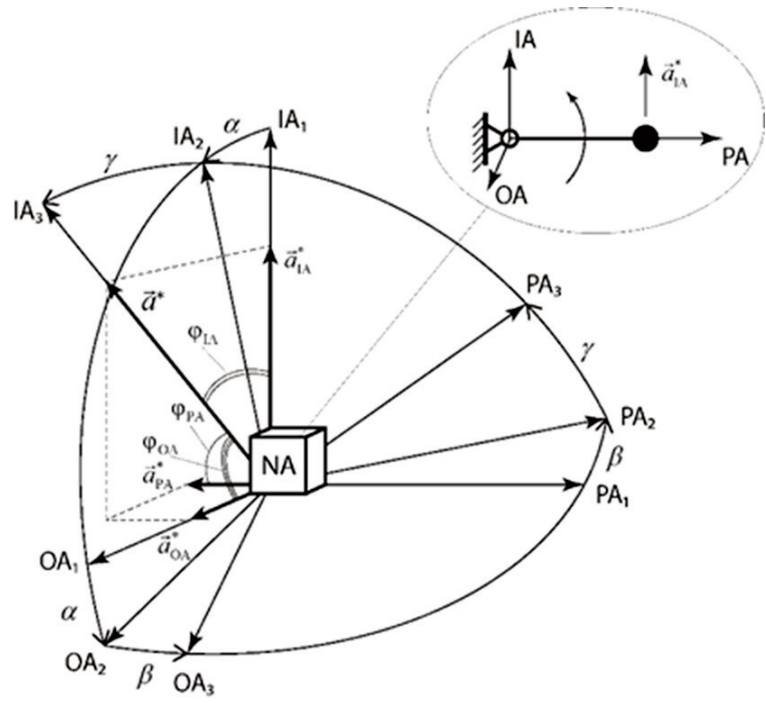

Fig. 1. Position of the acceleration vector relative to the accelerometer's instrumental axes: IA - input axis; $\mathrm{PA}$ - pendulum axis; $\mathrm{OA}$ - output axis (the axis of rotation of the sensing element). 
The seeming acceleration $\vec{a}(t)$, measured by the navigation accelerometer, includes the systematic component $\vec{a}(t)=E[\vec{a}(t)]$ (where $E[x]$ - the expected value operator) and the vibration $\vec{w}(t)$, whose average value physically equals to zero. That means it does not cause the object and its structural elements to move during operation time:

$$
x=\int_{0}^{T} \int \vec{w}(t) d t=\frac{w_{\mathrm{CP}} T^{2}}{2} \approx 0
$$

Thus, the error caused by the output nonlinearity (1) and described as:

$$
\begin{aligned}
& \Delta(\vec{a})=\frac{U(\vec{a})}{K_{1}}-\left(a_{\mathrm{IA}}+k_{0}\right)=\frac{k_{1}^{\prime}}{2} a_{\mathrm{IA}} \operatorname{sign} a_{\mathrm{IA}}+\sum_{n \geq 2} k_{n} a_{\mathrm{IA}}^{n}+\delta_{\mathrm{OA}} a_{\mathrm{PA}}+\delta_{\mathrm{PA}} a_{\mathrm{OA}}+ \\
& +k_{\mathrm{IP}} a_{\mathrm{IA}} a_{\mathrm{PA}}+k_{\mathrm{IO}} a_{\mathrm{IA}} a_{\mathrm{OA}}+k_{\mathrm{PO}} a_{\mathrm{PA}} a_{\mathrm{OA}}+k_{\mathrm{PP}} a_{\mathrm{PA}}^{2}+k_{\mathrm{OO}} a_{\mathrm{OA}}^{2},[\mathrm{~g}]
\end{aligned}
$$

includes two components:

$\Delta=\Delta_{\mathrm{BE}}+\Delta_{\mathrm{VE}},[\mathrm{g}]$

where: $\Delta_{\mathrm{BE}}$, [g] - the basic error of the navigational accelerometer caused by the nonlinearity of its metrological model; $\Delta_{\mathrm{VE}}$, [g] - the additional vibration error (VE) of the accelerometer as a result of the onboard vibration existence. Vibration error depends on both acceleration components:

$$
\Delta_{\mathrm{B \Pi}}=f\left(\vec{w}(t), \vec{a}_{0}(t)\right),[\mathrm{g}]
$$

Let's consider the harmonic vibration case for a more apparent examination of this dependence. In this case, the systematic deviation due to the sensitivity asymmetry is determined as:

$$
\begin{aligned}
\left\langle u_{\mathrm{AS}}\right\rangle & =\left\langle\frac{k_{1}^{\prime}}{2}\left(a_{\mathrm{IA}}+w_{\mathrm{IA}} \sin \omega t\right) \operatorname{sign}\left(a_{\mathrm{IA}}+w_{\mathrm{IA}} \sin \omega t\right)\right\rangle= \\
& =\frac{k_{1}^{\prime} \omega}{4 \pi} \operatorname{sign}\left(a_{\mathrm{IA}}+w_{\mathrm{IA}} \sin \omega t\right) \int_{0}^{2 \pi / \omega}\left(a_{\mathrm{IA}}+w_{\mathrm{IA}} \sin \omega t\right) d t,[\mathrm{~g}]
\end{aligned}
$$

The appearance in (2) of the nonlinear function $\operatorname{sign}(x)$ causes the dependence of the desired vibration error magnitude on the ratio of measured acceleration projection $a_{\mathrm{IA}}$ to vibration projection $w_{\mathrm{IA}}$ :

$$
\left\langle u_{\mathrm{AS}}\right\rangle=\left\{\begin{array}{l}
\frac{k_{1}^{\prime}}{2}\left|a_{\mathrm{IA}}\right|, \text { if }\left|a_{\mathrm{IA}}\right| \geq\left|w_{\mathrm{IA}}\right| ; \\
\frac{k_{1}^{\prime}}{2}\left[a \sin \frac{a_{\mathrm{IA}}}{w_{\mathrm{IA}}}+\sqrt{w_{\mathrm{IA}}^{2}-a_{\mathrm{IA}}^{2}}\right], \text { if }\left|a_{\mathrm{IA}}\right|<\left|w_{\mathrm{IA}}\right| .
\end{array},[\mathrm{g}]\right.
$$

The vibration detection caused by nonlinear coefficients $k_{n}(n \geq 2)$ is mathematically described as:

$$
\begin{aligned}
& \left\langle u_{\mathrm{NL}}\right\rangle=\left\langle\sum_{i=2}^{n} k_{i}\left(a_{\mathrm{IA}}+w_{\mathrm{IA}} \sin \omega t\right)^{i}\right\rangle=k_{2}\left(a_{\mathrm{IA}}^{2}+\frac{w_{\mathrm{IA}}^{2}}{2}\right)+k_{3}\left(a_{\mathrm{IA}}^{3}+\frac{3}{2} a_{\mathrm{IA}} w_{\mathrm{IA}}^{2}\right)+ \\
& +k_{4}\left(a_{\mathrm{IA}}^{4}+3 a_{\mathrm{IA}}^{2} w_{\mathrm{IA}}^{2}+\frac{3}{8} w_{\mathrm{IA}}^{4}\right),[\mathrm{g}]
\end{aligned}
$$


The error caused by non-orthogonality of OA and PA relative to IA does not contain vibrationdependent components:

$$
\left\langle u_{\delta}\right\rangle=\left\langle\delta_{\mathrm{OA}}\left(a_{\mathrm{PA}}+w_{\mathrm{PA}} \sin \omega t\right)+\delta_{\mathrm{PA}}\left(a_{\mathrm{OA}}+w_{\mathrm{OA}} \sin \omega t\right)\right\rangle=\delta_{\mathrm{OA}} a_{\mathrm{PA}}+\delta_{\mathrm{PA}} a_{\mathrm{OA}},[\mathrm{g}]
$$

In contrast, the detection of vibration by the cross-sensitivity coefficients takes place only if the vibration axis is not parallel to any of the instrumental axes of the accelerometer:

$$
\left\langle u_{\mathrm{cc}}\right\rangle=k_{\mathrm{IP}} a_{\mathrm{IA}} a_{\mathrm{PA}}+k_{\mathrm{IO}} a_{\mathrm{IA}} a_{\mathrm{OA}}+k_{\mathrm{PO}} a_{\mathrm{PA}} a_{\mathrm{OA}}+\frac{1}{2} k_{\mathrm{IO}} w_{\mathrm{IA}} w_{\mathrm{OA}}+\frac{1}{2} k_{\mathrm{IP}} w_{\mathrm{IA}} w_{\mathrm{PA}}+\frac{1}{2} k_{\mathrm{PO}} w_{\mathrm{PA}} w_{\mathrm{OA}},[\mathrm{g}]
$$

Therefore, the component of the vibrational error based on $(3-6)$ is described by the dependence as follows: 3

$$
\begin{aligned}
\Delta_{\mathrm{B \Pi}}= & \frac{k_{2}}{2} w_{\mathrm{IA}}^{2}+\frac{3}{2} k_{3} w_{\mathrm{IA}}^{2} a_{\mathrm{IA}}+3 k_{4} a_{\mathrm{IA}}^{2} w_{\mathrm{IA}}^{2}+\frac{3}{8} k_{4} w_{\mathrm{IA}}^{4}+\frac{k_{\mathrm{IO}}}{2} w_{\mathrm{IA}} w_{\mathrm{OA}}+\frac{k_{\mathrm{IP}}}{2} w_{\mathrm{IA}} w_{\mathrm{PA}}+ \\
+ & \frac{k_{\mathrm{PO}}}{2} w_{\mathrm{PA}} w_{\mathrm{OA}}+\left\{\begin{array}{l}
0, \text { when }\left|a_{\mathrm{IA}}\right| \geq\left|w_{\mathrm{IA}}\right| ; \\
\frac{k_{1}^{\prime}}{\pi}\left[a \cos \frac{a_{\mathrm{IA}}}{w_{\mathrm{IA}}}+\sqrt{w_{\mathrm{IA}}^{2}-a_{\mathrm{IA}}^{2}}-\frac{\pi\left|a_{\mathrm{IA}}\right|}{2}\right], \text { when }\left|a_{\mathrm{IA}}\right|<\left|w_{\mathrm{IA}}\right|
\end{array}\right.
\end{aligned}
$$

which can be generalized to the broadband random vibration case:

$$
\begin{aligned}
& \Delta_{\mathrm{VE}}=k_{2} S_{\mathrm{IA}} \Delta f+3 k_{3} a_{\mathrm{IA}} S_{\mathrm{IA}} \Delta f+6 k_{4} a_{\mathrm{IA}}^{2} S_{\mathrm{IA}} \Delta f+3 k_{4}\left(S_{\mathrm{IA}} \Delta f\right)^{2}+k_{\mathrm{IO}} \sqrt{S_{\mathrm{IA}} S_{\mathrm{OA}} \Delta f}+ \\
& +k_{\mathrm{IP}} \sqrt{S_{\mathrm{IA}} S_{\mathrm{PA}} \Delta f}+k_{\mathrm{PO}} \sqrt{S_{\mathrm{PA}} S_{\mathrm{OA}} \Delta f}+\left\{\begin{array}{l}
0, \text { if }\left|a_{\mathrm{IA}}\right| \geq \sqrt{S_{\mathrm{IA}} \Delta f} \\
\frac{k_{1}^{\prime}}{\pi}\left[a \sin \frac{a_{\mathrm{IA}}}{\sqrt{S_{\mathrm{IA}} \Delta f}}+k_{\mathrm{IP}} \sqrt{S_{\mathrm{IA}} \Delta f-a_{\mathrm{IA}}^{2}}-\frac{\pi\left|a_{\mathrm{IA}}\right|}{2}\right], \text { if }\left|a_{\mathrm{IA}}\right|<\sqrt{S_{\mathrm{IA}} \Delta f}
\end{array}\right.
\end{aligned}
$$

As you can see, the overall expression structure for the definition of the VE has not changed, but its arguments are the standard deviations of the vibration components:

$$
\sigma_{j}=\sqrt{S_{j} \Delta f_{j}},(j=\overline{\mathrm{PA}, \mathrm{IA}, \mathrm{OA}})
$$

where: $S_{j}$, $\left[g^{2} / \mathrm{c}\right]$ - is the spectral vibration density; $\Delta f_{j}$, $[1 / \mathrm{c}]-$ the frequency range of vibration.

The models (8) and (9) to calculate the vibration error (2) accelerometer containing components due to the presence in the model of its output (1) ratio of sensitivity asymmetry $k_{1}^{\prime}$, coefficients nonlinearity $k_{2}, k_{3}$ and $k_{4}$ angle along nonorthogonality $\delta_{\mathrm{OA}}, \delta_{\mathrm{PA}}$ and coefficients cross-sensitivity $k_{\mathrm{IP}}$, $k_{\mathrm{IO}}$, and $k_{\mathrm{PO}}$.

To calculate the VE according to formulas (8) and (9), it is suggested that the above coefficients be determined experimentally in static accelerometer tests by the method described in the following paragraph.

\section{Method of identification of vibration error of accelerometer}

The coefficients of models (8) and (9) are determined during acceptance tests by the known testpositioning method in the terrestrial gravitational field [5].

This test is divided into three rotation series depending on which axis accelerometer coincides with the axis of rotation (Fig. 2). The proposed test outline allows us to obtain enough algebraic equations for 
determining each coefficient of the VE model (8) or (9). As a result of the measurements in certain test positions, we get 24 values of the accelerometer output $U_{i j}(i=\overline{1,3}, j=\overline{1,8})$.

Firstly, an estimation of the sensitivity coefficient $\tilde{K}_{1}$ is performed:

$\tilde{K}_{1} \approx \frac{1}{6}\left[U_{15}-U_{11}+\sqrt{2}\left(U_{14}+U_{16}-U_{12}-U_{18}\right)\right],[\mathrm{out} / \mathrm{g}]$
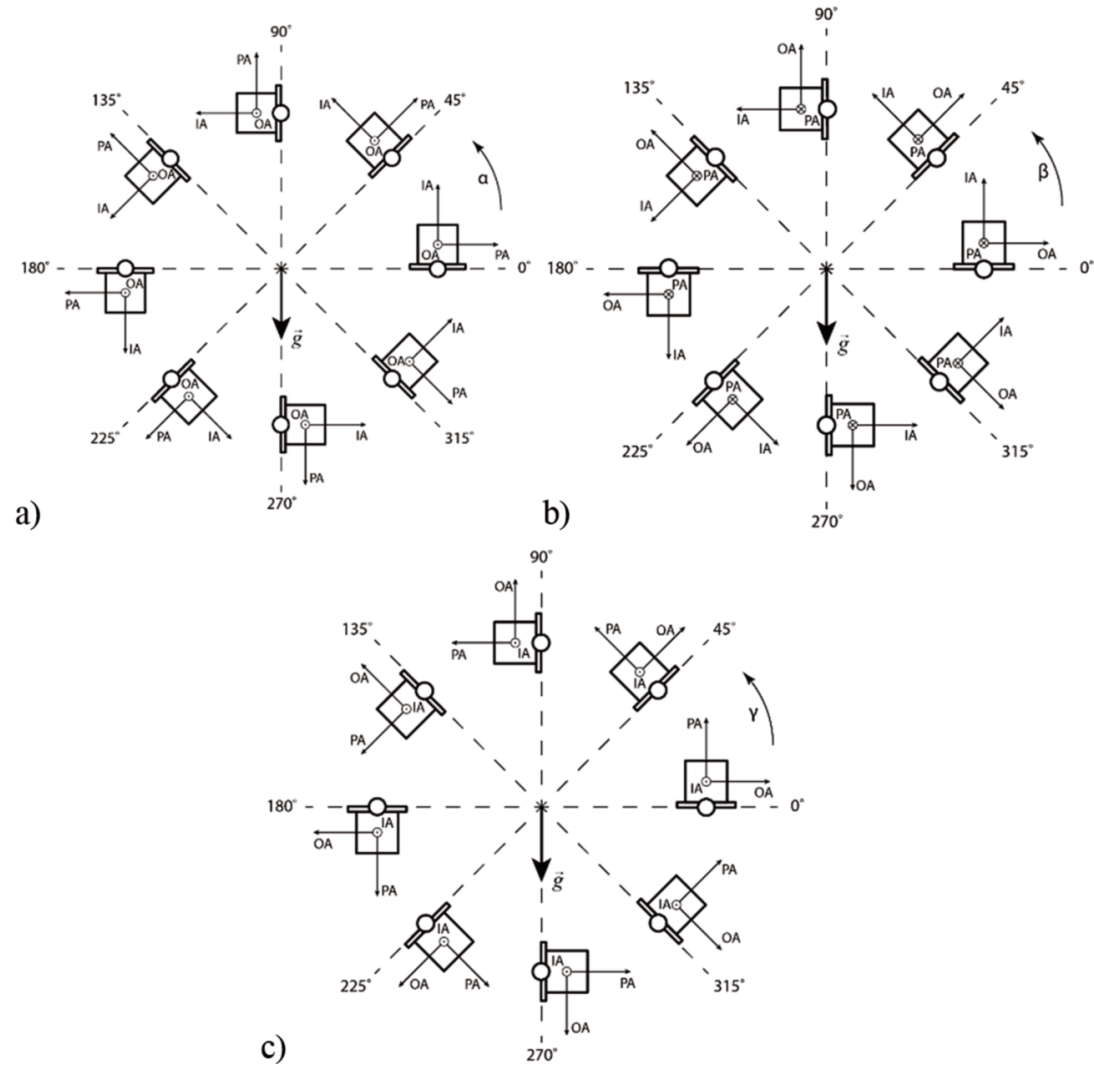

Fig. 2. Position the accelerometer and the first (a), second (b) and third (c) series of test maneuvers.

Since (10) contains the component dependent on cubic nonlinearity, the methodological error of determination $K_{1}$ is:

$\delta_{K 1}=\frac{\tilde{K}_{1}-K_{1}}{K_{1}}=\frac{2}{3} k_{3}$

which is determined by the following expression:

$$
k_{3}=\frac{\frac{\sqrt{2}}{\tilde{K}_{1}}\left(U_{16}-U_{12}-\frac{\sqrt{2}}{2}\left(U_{17}-U_{13}\right)\right)-2}{1-\frac{2 \sqrt{2}}{3 \tilde{K}_{1}}\left(U_{16}-U_{12}-\frac{\sqrt{2}}{2}\left(U_{17}-U_{13}\right)\right)},\left[\frac{1}{\mathrm{~g}^{2}}\right]
$$


The refined estimate of the conversion factor, according to (11), is equal to:

$K_{1}=\frac{\tilde{K}_{1}}{1+\frac{2}{3} k_{3}},\left[\frac{\text { out }}{\mathrm{g}}\right]$

An approximate estimation of the sensitivity asymmetry coefficient $k_{1}^{\prime}$ is:

$\tilde{k}_{1}^{\prime}=\frac{\tilde{K}_{1}^{(+)}+\tilde{K}_{1}^{(-)}}{K_{1}},[1]$

where:

$\tilde{K}_{1}^{(-)} \approx \frac{1}{6}\left(U_{15}+U_{25}+\sqrt{2}\left(U_{14}+U_{16}+U_{24}+U_{26}\right)-\frac{1+2 \sqrt{2}}{2}\left(U_{13}+U_{17}+U_{23}+U_{27}\right)\right),\left[\frac{\text { out }}{\mathrm{g}}\right]$

$\tilde{K}_{1}^{(+)} \approx \frac{1}{6}\left(U_{11}+U_{21}+\sqrt{2}\left(U_{12}+U_{18}+U_{22}+U_{28}\right)-\frac{1+2 \sqrt{2}}{2}\left(U_{13}+U_{17}+U_{23}+U_{27}\right)\right),\left[\frac{\text { out }}{\mathrm{g}}\right]$

The methodical assessment error is:

$\Delta_{K 1}^{\prime}=\tilde{k}_{1}^{\prime}-k_{1}^{\prime}=\frac{1}{3}\left[2(1+\sqrt{2}) k_{2}+(2+\sqrt{2}) k_{4}\right],[1]$

Where $k_{2}$ and $k_{4}$ are defined as the solution of the system of equations of the form:

$\left\{\begin{array}{l}a_{11} k_{2}+a_{12} k_{4}=b_{1} \\ a_{21} k_{2}+a_{22} k_{4}=b_{2}\end{array}\right.$

where:

$$
\begin{gathered}
a_{11}=-\frac{\sqrt{2}}{3} ; \quad a_{12}=-\frac{1}{3}(\sqrt{2}+1) ; \quad b_{1}=\frac{1}{K_{1}}\left(U_{12}+U_{14}+U_{16}+U_{18}-\frac{U_{11}+U_{15}}{2}\right) ; \\
a_{21}=\frac{2}{3} ; \quad a_{22}=1+\frac{\sqrt{2}}{3} ; \quad b_{2}=\frac{1}{K_{1}}\left(U_{11}+U_{15}-\left(U_{12}+U_{14}+U_{16}+U_{18}\right)\right) .
\end{gathered}
$$

Therefore, an exact estimate of the coefficient $k_{1}^{\prime}$, according to (13), is equal to:

$k_{1}^{\prime}=\tilde{k}_{1}^{\prime} \frac{1}{3}\left[2(1+\sqrt{2}) k_{2}+(2+\sqrt{2}) k_{4}\right],[1]$

The expression for zero offset calculus is as follows:

$k_{0}=\frac{1}{12 \cdot K_{1}}\left(U_{13}+U_{23}+U_{17}+U_{27}+\sum_{i=1}^{8} U_{3 i}\right),[\mathrm{g}]$

Expressions for calculating non-orthogonality angles $\delta_{\mathrm{PA}}$ and $\delta_{\mathrm{OA}}$ are:

$\delta_{\mathrm{PA}}=\frac{U_{27}+U_{37}-U_{23}-U_{33}}{4 K_{1}},[1] ; \quad \delta_{\mathrm{OA}}=\frac{U_{17}+U_{35}-U_{13}-U_{31}}{4 K_{1}},[1]$ 
Factors cross-sensitivity; $k_{\mathrm{IP}}, k_{\mathrm{IO}}, k_{\mathrm{PO}}$ defined by the following expressions:

$$
\begin{gathered}
k_{\mathrm{IP}}=\frac{U_{12}+U_{16}-U_{14}-U_{18}}{2 K_{1}},\left[\frac{1}{g}\right] ; k_{\mathrm{IO}}=\frac{U_{22}+U_{26}-U_{24}-U_{28}}{2 K_{1}},\left[\frac{1}{g}\right] ; \\
k_{\mathrm{PO}}=\frac{U_{32}+U_{36}-U_{34}-U_{38}}{2 K_{1}},[1 / g]
\end{gathered}
$$

After the experimental determining of the unknown coefficients of the model (1), the vibration error can be determined by formulas (8) and (9) for any vibration with known stochastic parameters.

\section{Experimental verification of the method}

The experimental quality verification of determining the coefficients of the model (1) and the subsequent VE estimation according to equations (8) and (9) was taken in comparing with results of vibration tests in cases of two high-precision accelerometers AKS-05M and A-15 and one mid-accuracy AL-1 (Fig. 3).
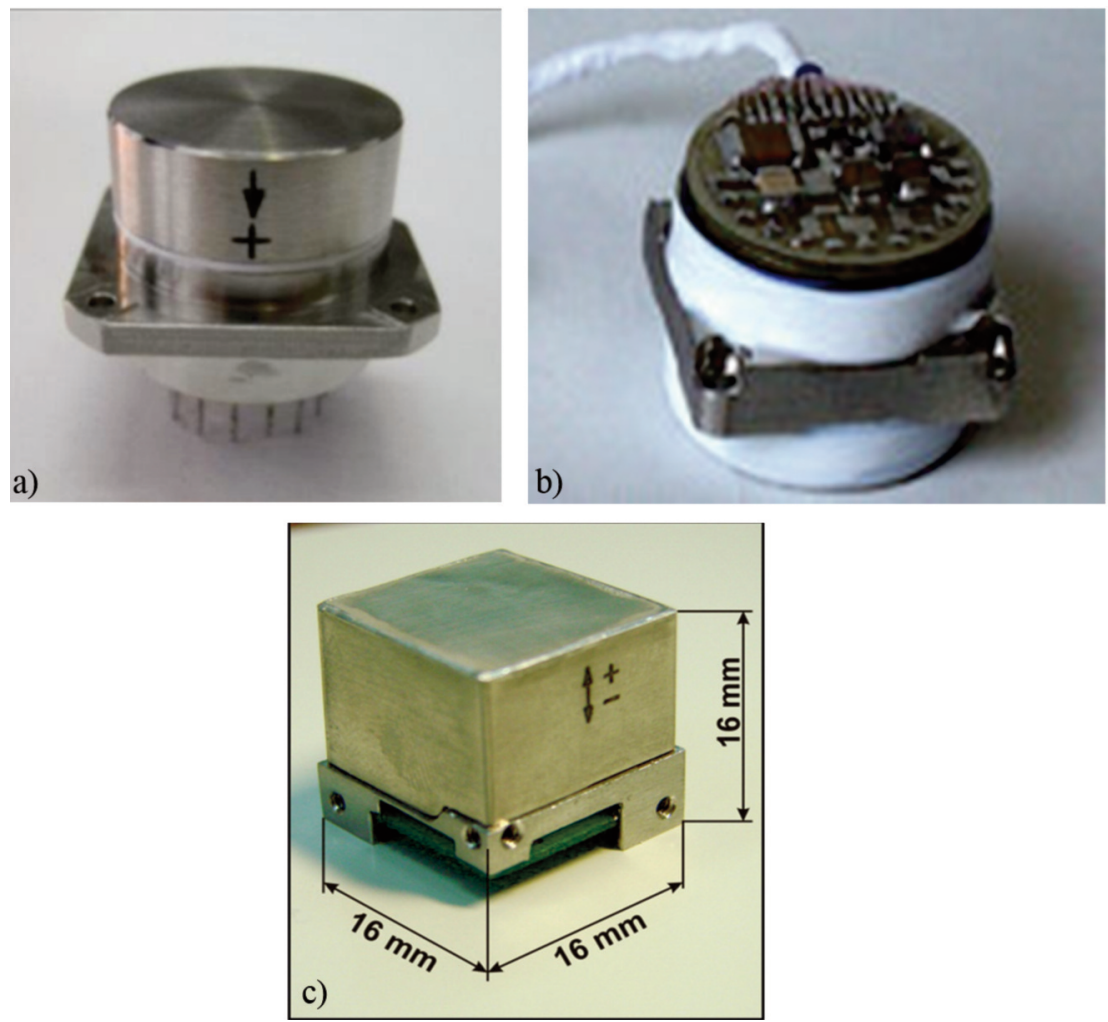

Fig. 3. Test accelerometers: AKS-05M (a), A-15 (b), and AL-1 (c).

The coefficients of the model (1) for these accelerometers have determined using the stand for static tests (Fig. 4). It includes an ODG-10 optical dividing head 1 (placed on a decoupled base 6) for test positioning of an accelerometer in the terrestrial gravitational field, which enables to set any angle of rotation with an error not exceeding $\pm 10^{\prime \prime}$. The testing accelerometer in a tilter 2 , which defines two perpendicular planes, is installed on the mounting surface of the shaft 5. 
This mounting surface is taken to the horizontal position using precision spirit level 4 with maximum error in range $\pm 10^{\prime \prime}$. The accelerometer output comes to the switchboard S. Its value is acquired by digitizing using the $\mathrm{ADC}$ and transmitted to the computational device $\mathrm{CD}$ for further statistical processing and estimating coefficients of the metrological model (1) according to equations (11-17).

The estimated values of all coefficients for each test accelerometer are given in table 1 . The corresponding calculated values of vibration error $\Delta_{\mathrm{B}}$, for the case of white noise vibration with $\sigma=1 g$ are given in table 2 .

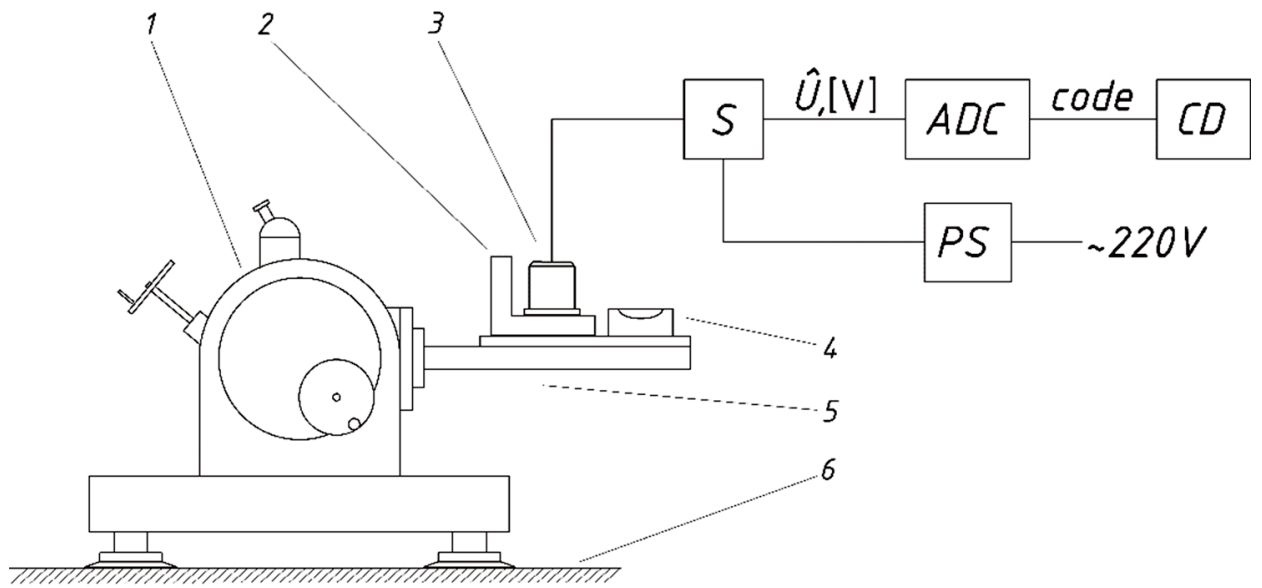

Fig. 4. The functional scheme of the stand for static tests: 1 - ODG-10;2 - tilter;

3 - tested accelerometer; 4 - spirit level; 5 - shaft with a mounting surface; 6 - decoupled base;

$\mathrm{S}$ - switchboard; ADC - analog-to-digital converter; CD - computational device;

PS - power supply.

Tab. 1. The estimated coefficients of model (1) accelerometers.

\begin{tabular}{|c|c|c|c|c|c|c|c|c|c|c|}
\hline Type of accel. & $\begin{array}{c}k_{0}, \\
10^{-4} \mathrm{~g}\end{array}$ & $\begin{array}{l}k_{1}, \\
10^{-4}\end{array}$ & $\begin{array}{c}k_{2}, \\
10^{-4} \mathrm{~g}^{-1}\end{array}$ & $\begin{array}{c}k_{3}, \\
10^{-4} \mathrm{~g}^{-2}\end{array}$ & $\begin{array}{c}k_{4}, \\
10^{-4} \mathrm{~g}^{-3}\end{array}$ & $\begin{array}{c}\delta_{\mathrm{PA}} \\
10^{-4} \mathrm{rad}\end{array}$ & $\begin{array}{c}\delta_{\mathrm{OA}} \\
10^{-4} \mathrm{rad}\end{array}$ & $\begin{array}{c}k_{\mathrm{IO}} \\
10^{-5} \mathrm{~g}^{-1}\end{array}$ & $\begin{array}{c}k_{\mathrm{IP}} \\
10^{-6} \mathrm{~g}^{-1}\end{array}$ & $\begin{array}{c}k_{\mathrm{PO}} \\
10^{-7} \mathrm{~g}^{-1}\end{array}$ \\
\hline AKS-05 & -0.07 & 3.015 & -2.56 & -1.20 & -1.20 & 3.90 & 3.05 & 1.1 & 1.1 & 0.001 \\
\hline A-15 & 0.12 & -6.850 & 0.50 & 1.12 & 1.12 & 9.01 & -5.02 & -1.0 & -1.0 & -0.002 \\
\hline AL-1 & -2.25 & -8.132 & 4.2 & -8.0 & -8.0 & 1.80 & 0.80 & 5.5 & 5.5 & 550.0 \\
\hline
\end{tabular}

Tab. 2. Vibrational errors of accelerometers.

\begin{tabular}{|c|c|c|c|}
\hline Type of accelerometer & AKS-05 & A-15 & AL-1 \\
\hline$\Delta_{\mathrm{B}}, 10^{-4} \mathrm{~g}$ & 1.8 & -8.0 & 15.5 \\
\hline$\hat{\Delta}_{\mathrm{B}}, 10^{-4} \mathrm{~g}$ & 2.8 & -6.7 & 21.0 \\
\hline
\end{tabular}

The efficiency of the proposed method for determining the vibration error has checked by comparing the estimated values $\Delta_{\mathrm{B}}$ (Tab. 2) with values $\hat{\Delta}_{\mathrm{B}}$ determined during the dynamic tests of accelerometers on the vibration stand (Fig. 5). 


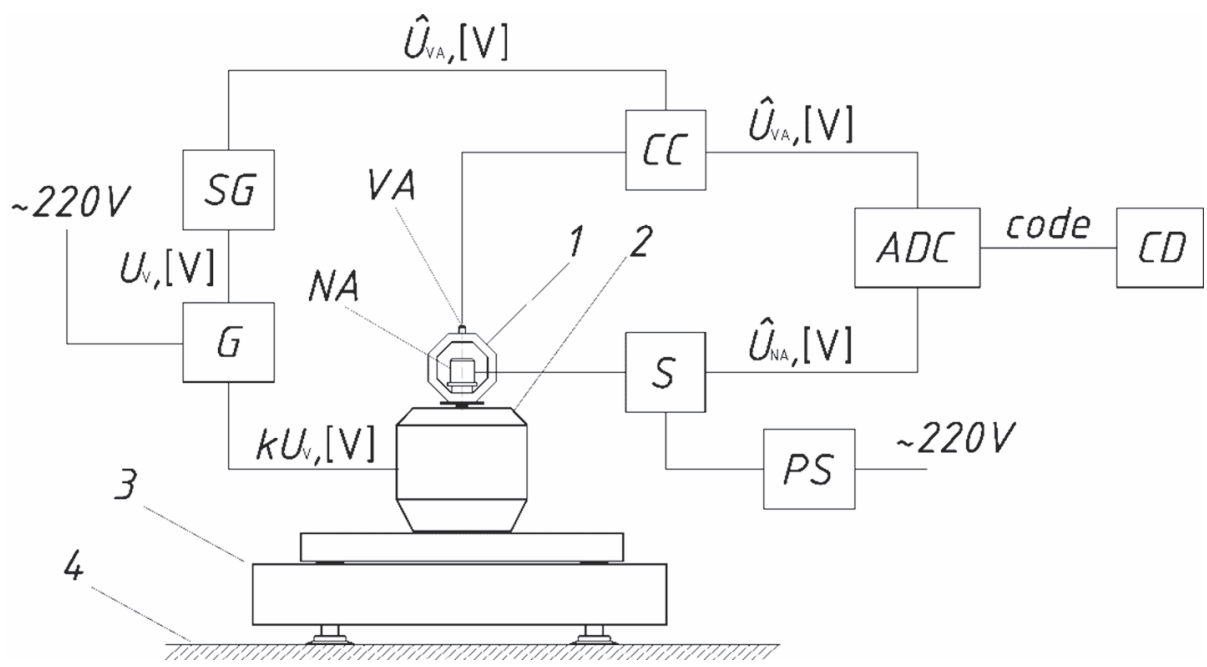

Fig. 5. The functional scheme of the stand for vibration tests: 1 - tilter; 2 - vibration machine; 3 - solid base; 4 - decoupled base; VA - vibrational accelerometer; NA - navigational accelerometer; $\mathrm{CC}$ - charge converter; $\mathrm{ADC}$ - analog-to-digital converter; $\mathrm{G}$ - gain; $\mathrm{CD}$ - computational device; SG - signal generator; PS - power supply.

In dynamic tests, the numerical value of vibration error is determined by integrating during vibration the accelerometer output signal $U(t)$ with the preliminary subtraction of its mean value $U_{0}$ before vibration:

$v(t)=\frac{1}{K_{1}} \int_{0}^{t}\left(U(t)-U_{0}\right) d t,[\mathrm{~g} \cdot \mathrm{s}]$

and consequent least-squares approximation of the result of this integration to a linear function:

$v(t)=\hat{\Delta}_{\mathrm{B}} \cdot t,[\mathrm{~g} \cdot \mathrm{s}]$

where the scale factor of this function is the numerical value of the vibration error (assuming that the magnitude of this error is unchanged during a specific dynamic test). The results of the determination of $\mathrm{VE}$ are also given in the table 2.

The estimated values of vibrational error generally match with experimental results (mismatch in the range $35 \%$ ), which confirms the effectiveness of the proposed method.

\section{CONCLUSIONS}

The obtained mathematical model $(8,9)$ of the navigation accelerometer vibration error contains both additive and multiplicative components and varies with the amplitude and frequency of the vibrations. The additive components are only dependent on the vibration value and determined by even nonlinear coefficients. The multiplicative components are dependent on measured acceleration and determined by the sensitivity asymmetry, the odd nonlinear coefficients, and the cross-sensitivity.

The proposed method allows estimating the vibration error during its static testing, without the risk of the mechanical sensing element damaging, which quite often occurs during dynamic tests. 


\title{
REFERENCES
}

[1] Konovalov, S.F., 1993, The theory of vibration resistance of accelerometers, Mechanical Engineering, Moscow.

[2] Afanasiev, A.S., Domrachev, V.G., Komarov, E.G., and Polushkin, V.M., 2013, "The method of control of vibration resistance of microelectromechanical converters of linear acceleration in a set of spatial orientations," Lesnoy Vestnik / Forestry Bulletin, 2(94), pp.135-139.

[3] Long Pham, and DeSimone, A., 2017, "Vibration Rectification in MEMS Accelerometers," Analog Devices, Inc., from:

https://www.analog.com/en/technical-articles/vibration-rectification-in-mems-accelerometers.html

[4] IEEE, 1998, "IEEE Standard Specification Format Guide and Test Procedure for Linear, SingleAxis, Nongyroscopic Accelerometers," IEEE Std. 1293-1998.

[5] Chernyak, N.G., Rybak, V.V., and Terokhin, S.V., 2014, "Instrumental errors of navigation accelerometer nonlinear metrological model's coefficients identification by the test-positioning method in the terrestrial gravitational field," Information systems, mechanics and control, 11, pp. 92-101.

\section{DOKŁADNOŚĆ NAWIGACYJNEGO AKCELEROMETRU Z NIELINIOWYM MODELEM METROLOGICZNYM W WARUNKACH PRACY}

\begin{abstract}
Abstrakt
Opracowano model matematyczny błędu akcelerometru nawigacyjnego spowodowany nieliniowością jego modelu metrologicznego, uwzględniający wpływ wibracji. Zaproponowano metodę eksperymentalnego oszacowania błędu wibracji w oparciu o opracowany model. Główną ideą metody jest ocena parametrów opracowanego modelu podczas prób statycznych w ziemskim polu grawitacyjnym i obliczenie błędu zgodnie ze specyficznymi cechami drgań - amplitudą w przypadku profilu drgań harmonicznych lub pasma częstotliwości i spektrum mocy gęstość w przypadku drgań losowych. Skuteczność proponowanej metody została przetestowana przy użyciu trzech rodzajów akcelerometrów nawigacyjnych w porównaniu z wynikami klasycznych testów dynamicznych w różnych warunkach drgań (harmoniczne, biały szum itp.).
\end{abstract}

Słowa kluczowe: akcelerometr nawigacyjny, błąd drgań, model metrologiczny, funkcja konwersji, identyfikacja współczynników, próba statyczna. 